\title{
Review
}

\section{Mesenchymal Stromal Cells to Regenerate Emphysema: On the Horizon?}

\author{
Dennis M.L.W. Kruk ${ }^{a, b}$ Irene H. Heijink ${ }^{a-c}$ Dirk-Jan Slebos ${ }^{b, c}$ Wim Timens $^{a-c}$ \\ Nick H. ten Hacken ${ }^{b, c}$ \\ aDepartment of Pathology and Medical Biology, University Medical Center Groningen, University of Groningen, \\ Groningen, The Netherlands; ${ }^{b}$ Groningen Research Institute for Asthma and COPD, University Medical Center \\ Groningen, University of Groningen, Groningen, The Netherlands; ' Department of Pulmonary Diseases, University \\ Medical Center Groningen, University of Groningen, Groningen, The Netherlands
}

\section{Keywords}

Emphysema - Stem cell transplantation - Alveolar wall destruction · Repair · Mesenchymal stromal cells

\begin{abstract}
Mesenchymal stem or stromal cells (MSCs) are multipotent cells that play a pivotal role in various phases of lung development and lung homeostasis, and potentially also lung regeneration. MSCs do not only self-renew and differentiate into renew tissues, but also have anti-inflammatory and paracrine properties to reduce damage and to support tissue regeneration, constituting a promising cell-based treatment strategy for the repair of damaged alveolar tissue in emphysema. This review discusses the current state of the art regarding the potential of MSCs for the treatment of emphysema. The optimism regarding this treatment strategy is supported by promising results from animal models. Still, there are considerable challenges before effective stem cell treatment can be realized in emphysema patients. It is difficult to draw definitive conclusions from the available animal studies, as different models, dosage protocols, administration routes, and sources of MSCs have been used with different measures of effectiveness. Moreover, the regrowth po-
\end{abstract}

tential of differentiated tissues and organs differs between species. Essential questions about MSC engraftment, retention, and survival have not been sufficiently addressed in a systematic manner. Few human studies have investigated MSC treatment for chronic obstructive pulmonary disease, demonstrating short-term safety but no convincing benefits on clinical outcomes. Possible explanations for the lack of beneficial effects on clinical outcomes could be the source (bone marrow), route, dosage, frequency of administration, and delivery (lack of a bioactive scaffold). This review will provide a comprehensive overview of the (pre)clinical studies on MSC effects in emphysema and discuss the current challenges regarding the optimal use of MSCs for cell-based therapies.

(c) 2018 The Author(s) Published by S. Karger AG, Basel

\section{Introduction}

Prompted by optimistic messages in the media, more and more emphysema patients now approach their general practitioner or their lung physician for treatment with stem cells. Those physicians in turn respond hesitat-

\begin{tabular}{|c|c|}
\hline KARGER & $\begin{array}{l}\text { (c) } 2018 \text { The Author(s) } \\
\text { Published by S. Karger AG, Basel }\end{array}$ \\
\hline $\begin{array}{l}\text { E-Mail karger@karger.com } \\
\text { www.karger.com/res }\end{array}$ & $\begin{array}{l}\text { This article is licensed under the Creative Commons Attribution- } \\
\text { NonCommercial-NoDerivatives } 4.0 \text { International License (CC BY- } \\
\text { NC-ND) (http://www.karger.com/Services/OpenAccessLicense). } \\
\text { Usage and distribution for commercial purposes as well as any dis- } \\
\text { tribution of modified material requires written permission. }\end{array}$ \\
\hline
\end{tabular}

Dennis M.L.W. Kruk, MSc

Department of Pathology and Medical Biology

University Medical Center Groningen, Hanzeplein 1

NL-9716 GZ Groningen (The Netherlands)

E-Mail d.m.l.w.kruk@umcg.nl 
ingly. Certain types of stem cell such as hematopoietic stem cell transplants have been proven to provide effective treatment for leukemia, lymphoma, or severe combined immunodeficiency. Additionally, in phase I and II clinical trials mesenchymal or stromal cells (MSCs) have been reported to exert beneficial effects on immunemediated diseases such as graft-versus-host disease and Crohn disease [1].

However, effects of using any type of stem cell in solid organ diseases like emphysema currently remain unproven. The question arises as to whether - and, if so, which - stem cells are capable of regenerating a destroyed emphysematous lung and repair it into the complex architecture of healthy lungs.

\section{The Complex Architecture of Healthy Lungs}

During the 5th week of gestation, the lung starts to develop from a bud of the foregut. Cell layers originating from the three germ layers come together in a parallel and serially linked network of tubes, strictly dictated by the genetic blueprint of the cells present. During this complex developmental process, several factors are essential, such as WNT ligands (WNT2, WNT3A, and WNT7B), fibroblast growth factors, keratinocyte growth factor, bone morphogenetic protein 4 , sonic hedgehog ligands, Notch ligands, retinoic acid, and transforming growth factor- $\beta$ [2]. The same factors also play an important role during various repair processes in adulthood [2]. Once mature, the lungs will contain approximately $250 \times 10^{9}$ cells, imbedded in a network of extracellular matrix (ECM) proteins including collagens, elastins, proteoglycans, fibronectins, and tenascins that give the lung structure, strength, and elasticity and regulate cell activities through integrin binding and signaling.

The gas exchange surface of the lungs, which is made up of over 300 million alveoli, is approximately $130 \mathrm{~m}^{2}$ in size. This gas exchange is mainly facilitated by alveolar type I (ATI) pneumocytes. They are flat-shaped epithelial cells that line the alveolar surface, together with ATII cells, which are cuboidal in shape and characterized by the production of surfactant proteins. ATII cells play an important role in maintaining structural integrity, reducing surface tension in the alveoli, and they also play an important role in alveolar regeneration, as they serve as progenitor cells for ATI cells. Every day, 1,500 L of blood flow passes by this surface through the extensive capillary network, exchanging $360 \mathrm{~L}$ of oxygen and carbon dioxide by passive diffusion across the small distance of the cellular membranes of ATI cells, the cellular membranes of endothelial cells, and the shared thin basal membrane.
Subtle regulatory mechanisms are in place to make certain that local ventilation and perfusion remain well balanced, ensuring that gas exchange units contribute in a positive manner to normoxic arterial blood gas levels. The above-described complexity of the lung is often cited by sceptics as the main hurdle to constructing new gas exchange units or a new lung, even with the aid of stem cells.

\section{Tissue Damage in Emphysema}

Chronic obstructive pulmonary disease (COPD) is a devastating, life-long, progressive lung disease that affects between 4 and $10 \%$ of the European population and will be the 3rd leading cause of death in 2030 according to the WHO. It is characterized by chronic inflammation present in all compartments of the lung. This leads to chronic bronchitis with mucus hypersecretion and airway wall thickening on the one hand, and parenchymal inflammation and loss of alveolar tissue, known as emphysema, on the other hand [3]. Emphysema is characterized by irreversible loss of alveolar tissue, air space enlargement, loss of lung elastic recoil, and accelerated lung function decline [4]. In end-stage emphysema, the gas exchange surface can be reduced by as much as $70 \%$.

The major risk factor for COPD is the inhalation of noxious substances, including cigarette smoke. Years of cigarette smoke exposure lead to the development of COPD in $~ 20 \%$ of smokers; thus, not all smokers are susceptible to COPD, indicating that a genetic component is involved as well. COPD patients may experience a drop in arterial oxygenation during even mild exercise. Furthermore, loss of elastic coil through loss of ECM in emphysema causes static hyperinflation of the lungs, which may increase dynamically during exercise. This contributes importantly to a patient's exercise-induced dyspnea. Recurring exacerbations, a sudden worsening of inflammation and disease symptoms often associated with microbial infection, may contribute to the progressive loss of lung tissue and lung function $[5,6]$.

Currently, there is no curative treatment available for COPD. Smoking cessation reduces the chronic bronchitis component of COPD, but the emphysematous tissue loss is irreversible. Chronic inflammation, including a dysregulation between proteolytic and antiproteolytic activity and an increased burden of oxidative stress, contributes to the loss of ECM, specifically loss of elastic fibers and proteoglycans [7]. In addition, increased apoptosis in structural alveolar cells, specifically ATII pneumocytes as well as endothelial cells [8], has been observed. Lung development as well as lung repair, e.g., upon injury in- 


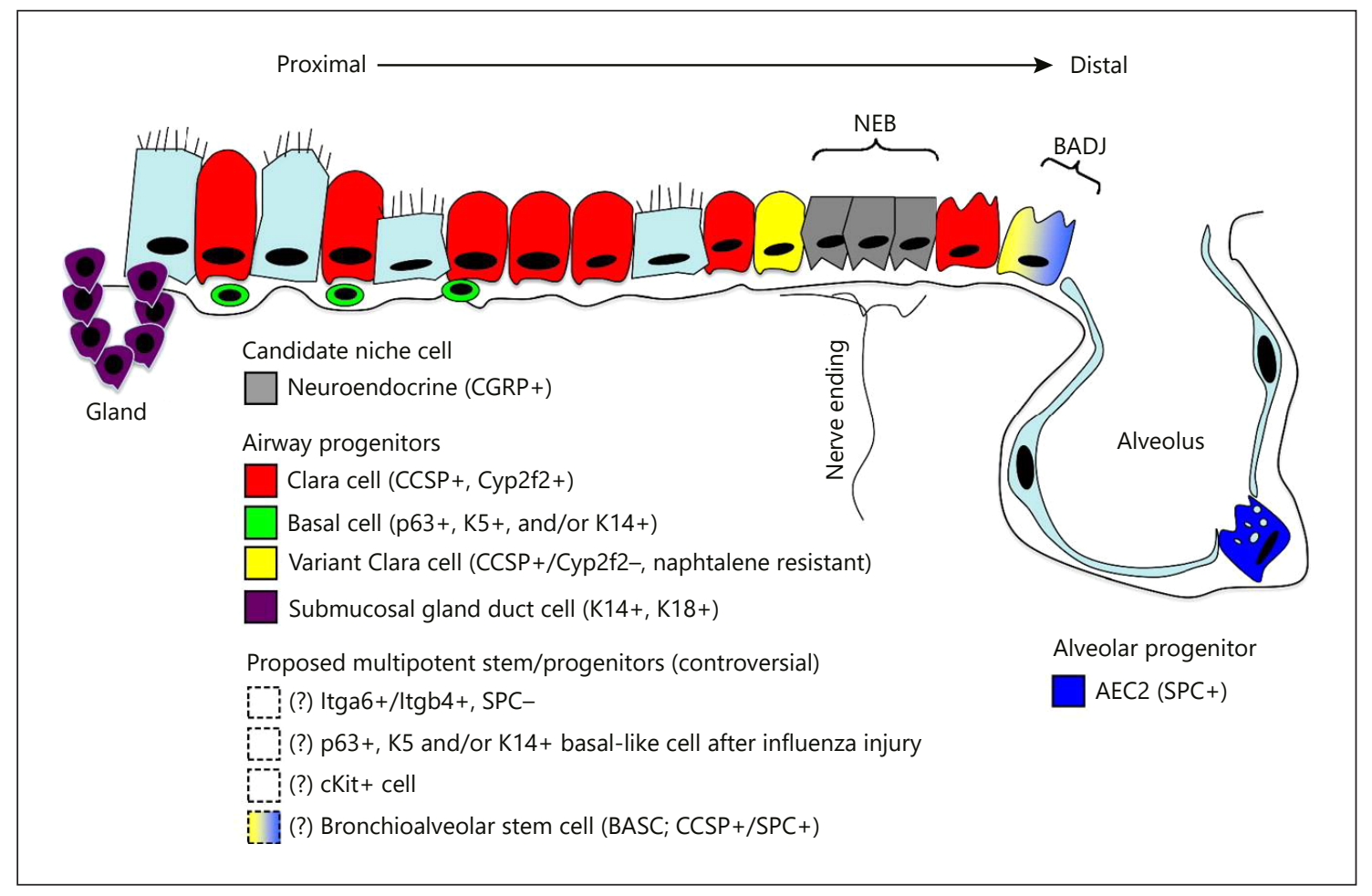

Fig. 1. Potential progenitor cells of the lung. Schematic overview of candidate epithelial progenitor cells of the lung, from proximal to distal. Candidate cells whose location is yet unknown are marked with dotted symbols or questions marks (?). AEC2, type 2 alveolar epithelial cell; BADJ, bronchoalveolar duct junction; NEB, neuroepithelial body; CCSP+, Clara cell secretory protein-positive cell; CGRP, calcitonin gene-related peptide; Itg, integrin; K, cytokeratin; SPC, surfactant protein C. Illustration reproduced with permission [11].

duced by cigarette smoking, involves close communication between epithelial progenitors and underlying mesenchymal cells. A reduced regenerative capacity of mesenchymal cells - for instance, caused by smoking-induced accelerated aging - could play an important role in this impaired alveolar regeneration in emphysema [9].

\section{The Role of Stem Cells in Lung Regeneration}

Lung regeneration can occur spontaneously, as evidenced by various clinical situations, and is thought to involve tissue-resident stem cell populations. In an example case report, a woman with a right-sided pneumonectomy showed an increase in vital capacity over the course of a 15 -year follow-up. The authors report a $64 \%$ increase in alveoli, as determined using serial CT scans and MRI [10]. However, the alveoli were more shallow than normal, and this study did not directly show stem cell involvement. Stem cells are noncommitted cells that in the adult stage are predominantly present in bone marrow and are characterized by their ability to differentiate into other cell types and sustain themselves in a process referred to as self-renewal. Stem cells can be more or less specialized in their lineage and are classified based on their ectodermal, mesodermal, or endodermal germ layer origin, as well as on their ability to differentiate into other cell types. This ranges from totipotent (the ability to differentiate into all cell types in the embryonic stage), pluripotent, and multipotent to oligopotent (the ability to differentiate into only one or two cell types). Oligopotent stem cells that are able to differentiate into other functional cell types are referred to as progenitor cells.

In the lungs, multiple types of residential progenitor cell for the epithelia have been identified [11], as depicted in Figure 1. Specific parts of the lungs are thought to be maintained by distinct stem cell populations. For instance, basal epithelial cells of the airways give rise to ciliated cells and goblet cells for mucociliary clearance of foreign particles, while type II alveolar epithelial cells are key cells for surfactant production and also serve as progenitors for type I alveolar epithelial cells. However, nich- 
es of multipotent stem cells within the human lung have not been extensively characterized. The first evidence for the presence of stem cells in the adult lung has come from a study where stem cells derived from human distal lung tissue were expanded in vitro and injected into damaged murine lungs, where they were shown to integrate structurally and to be functional with the damaged lung [10]. This observation has not yet been replicated by others, although it accelerated the optimism regarding future stem cell treatment for emphysema.

MSCs are multipotent stem cells originating from the mesoderm and residing in various tissues including bone marrow, adipose tissue, muscle, and the lung. MSCs currently receive a lot of attention for their therapeutic capacity. They not only contribute to tissue renewal, but also support site-specific epithelial and endothelial responses through paracrine effects, secreting growth factors (e.g., fibroblast growth factors, WNT ligands, hepatocyte growth factor, vascular endothelial growth factor, and transforming growth factor- $\beta$ ) and ECM proteins (including elastins), and have a local anti-inflammatory capacity (secretion of IL-10, PGE2, IL1RA, IDO, and microRNAs, for instance). Because of their immunosuppressive effects, MSCs do not elicit an allogeneic immune response when administered either homologously or heterologously. The identification and verification of MSCs is notoriously challenging, as many of the markers that identify MSCs are also expressed by other mesenchymal cells such as fibroblasts. The international standard for MSCs uses a number of criteria to identify these cells, such as the ability to differentiate in vitro into adipocytes, chondrocytes, and osteoblasts or smooth muscle cells [12]. For instance, Liu et al. [13] and Gong et al. [14] described the ability of MSCs to differentiate into ATII cells, which in turn can differentiate into ATI cells. However, these findings are still controversial and may rely on an in vitro artifact, while in vivo evidence on MSC differentiation into ATII cells is still lacking. The current consensus in the literature is to refer to these cells as stromal rather than stem cells, despite their regenerative characteristics.

\section{MSC Treatment in Preclinical Models of Emphysema}

Animal studies may give important clues as to whether MSC administration is able to repair or regenerate emphysematous lung tissue, and may indicate the best source, route, and dose of administration. Various studies have described the potential of MSCs to contribute to re- pair of lung tissue damage and/or suppress inflammatory and fibrotic processes. Here we will focus on models that described the potential of MSCs in mouse models of emphysema. To the best of our knowledge, currently 16 studies have described the effect of MSCs in animal models of emphysematous lung damage.

\section{Effects of MSC Treatment in Different Models}

Different models have been used to study effects of MSCs in emphysema (see Table 1 for an overview). The most frequently used model where the therapeutic potential of MSCs was studied was intratracheal instillation of pancreatic elastase into mice to induce lung damage mimicking emphysema [15]. Elastase cleaves elastin fibers, leading to a reduced elastin content, and causes alveolar lesions as seen in emphysema patients [16].

Different studies used a variable number of exposures to elastase (1-5 times), as well as variable time frames before testing treatment effects. For example, Tibboel et al. [17] used a single bronchial instillation of porcine pancreatic elastase and tested the effects of mouse-derived bone marrow-derived MSCs (BM-MSCs) within $24 \mathrm{~h}$ upon instillation of elastase, thus reflecting effects of acute damage. Here, BM-MSC administration reduced the deterioration of lung function, but only when installed intravenously, not intratracheally. By contrast, Ingenito et al. [18] induced emphysema by a monthly bronchial instillation of porcine pancreatic elastase for 5 months in a large animal (ovine) model before testing the effects of autologous lung-derived MSCs (L-MSCs) 28 days after the last installation. They demonstrated that L-MSCs have beneficial effects, normalizing lung tissue architecture and increasing ECM deposition upon elastase-induced injury [18].

Collectively, intravenous or intratracheal administration of mouse-derived BM-MSCs as well as L-MSCs has been demonstrated to reduce elastase-induced damage in 5 different studies (Table 2). Furthermore, humanderived BM-MSCs were recently shown to reduce alveolar damage in an elastase mouse model of emphysema (6 doses over 2 weeks [19]).

Papain was used in 2 other studies to model emphysema and study the effect of MSC administration [20,21]. This cysteine protease cleaves peptides and has a very broad spectrum of substrates including proteins, antibodies, and ECM components. Although papain cleaves another spectrum of substrates than elastase, it induces elastase-like features of emphysema, as suggested by comparable mean linear intercept measurements in mice $[10,12]$. Intratracheal administration of BM-MSCs has 
Table 1. Animal models used for studies on MSC treatment of emphysema

\begin{tabular}{|c|c|c|c|c|}
\hline Ref./year & $\begin{array}{l}\text { Model } \\
\text { organism }\end{array}$ & Inductor method(s) & Inductor dose information & Time before MSC administration \\
\hline $24 / 2011$ & Mouse & $\begin{array}{l}\text { VEGFR inhibitor } \\
\text { Cigarette smoke exposure }\end{array}$ & $\frac{1 \times, 20 \mathrm{mg} / \mathrm{kg}}{\text { Daily for } 4 \text { months }}$ & $\begin{array}{l}\text { After } 2 \text { months of cigarette smoke } \\
\text { exposure }\end{array}$ \\
\hline $25 / 2011$ & Mouse & Porcine pancreatic elastase & $1 \times, 1.5 \mathrm{IU}$ & $6-7$ weeks \\
\hline $18 / 2012$ & Sheep & High-purity porcine elastase & $\begin{array}{l}5 \times, 200 \mathrm{U} / \mathrm{mL} \\
20 \mathrm{~mL} / \text { dose }\end{array}$ & 8 weeks after final instillation \\
\hline $22 / 2011$ & Rat & Cigarette smoke exposure & $\begin{array}{l}20 \text { cigarettes/day } \\
5 \text { days/week } \\
\text { for } 6 \text { months }\end{array}$ & After 6 months of exposure \\
\hline $23 / 2015$ & Rat & Cigarette smoke exposure & $\begin{array}{l}20 \text { cigarettes/day } \\
5 \text { days/week } \\
\text { for } 12 \text { weeks }\end{array}$ & $\begin{array}{l}\text { After } 7 \text { weeks of cigarette smoke } \\
\text { exposure }\end{array}$ \\
\hline $28 / 2013$ & Mouse & Elastase & $1 \times$ & 3 weeks \\
\hline $30 / 2014$ & Mouse & Porcine pancreatic elastase & $\begin{array}{l}1 \times / \text { week } \\
\text { for } 4 \text { weeks } \\
0.1 \mathrm{IU}\end{array}$ & $3 \mathrm{~h}$ after last instillation \\
\hline $32 / 2011$ & Mouse & Porcine pancreatic elastase & $1 \times, 0.01 \mathrm{U} / \mathrm{g}$ body weight & 2 weeks \\
\hline $17 / 2014$ & Mouse & Porcine pancreatic elastase & $1 \times, 4.8 \mathrm{U} / 100 \mathrm{~g}$ body weight & $\begin{array}{l}24 \mathrm{~h} \text { before, } 24 \mathrm{~h} \text { after, and } 21 \text { days } \\
\text { after instillation }\end{array}$ \\
\hline $33 / 2015$ & Mouse & Porcine pancreatic elastase & $1 \times, 1.5 \mathrm{mg} / \mathrm{kg}$ body weight & 2 weeks \\
\hline $47 / 2015$ & Mouse & Porcine pancreatic elastase & $1 \times, 0.4 \mathrm{U}$ & 1 week \\
\hline $34 / 2014$ & Mouse & Porcine pancreatic elastase & $1 \times, 0.4 \mathrm{U}$ & 1 week \\
\hline $21 / 2008$ & Rat & Papain & $1 \times, 0.05 \mathrm{~mL} / 100 \mathrm{~g}$ body weight & Immediately after instillation \\
\hline $20 / 2010$ & Rat & Papain & $1 \times, 8 \%$ in $\mathrm{PBS}$ & $2 \mathrm{~h}$ after instillation \\
\hline $36 / 2006$ & Rat & Porcine pancreatic elastase & $1 \times, 25 \mathrm{U} / 100 \mathrm{~g}$ body weight & 7 days \\
\hline $35 / 2006$ & Rat & Porcine pancreatic elastase & $1 \times, 25 \mathrm{U} / 100 \mathrm{~g}$ body weight & 7 days \\
\hline
\end{tabular}

MSC, mesenchymal stromal cell; VEGFR, vascular endothelial growth factor receptor.

been demonstrated to reduce papain-induced damage and reduce alveolar apoptosis $[20,21]$ (Table 2).

Cigarette smoke exposure has been used in 3 other studies where effects of MSCs were assessed [22-24]. Long-term daily cigarette exposure using whole body exposure of mouse strains that are susceptible to the detrimental effects of smoke mimics chronic cigarette smoking as seen in COPD patients more closely than the acute effects of installation of proteases, inducing neutrophilia as well as emphysematous lesions. Administration of MSCs reduced cigarette smoke-induced damage in all 3 studies (Table 2). In both COPD patients and mice, the increased and chronic burden of oxidative stress upon cigarette smoking has been shown to cause mitochondrial damage in lung epithelial cells $[25,26]$. In a rat model of cigarette smoke-induced lung damage, Li et al. [27] observed that intravenously injected human-induced pluripotent stem cell-derived MSCs as well as BM-MSCs attenuated lung damage, reducing the mean linear intercept. The authors proposed that these beneficial effects are mediated, at least in part, by mitochondrial transfer of MSCs to epithelial cells, as they have demonstrated that this process can occur in vitro. However, whether mitochondrial transfer also occurs in vivo and to what extent it contributes to the observed beneficial effects of MSCs remains unknown. 
Table 2. MSC treatment of emphysema in animal models

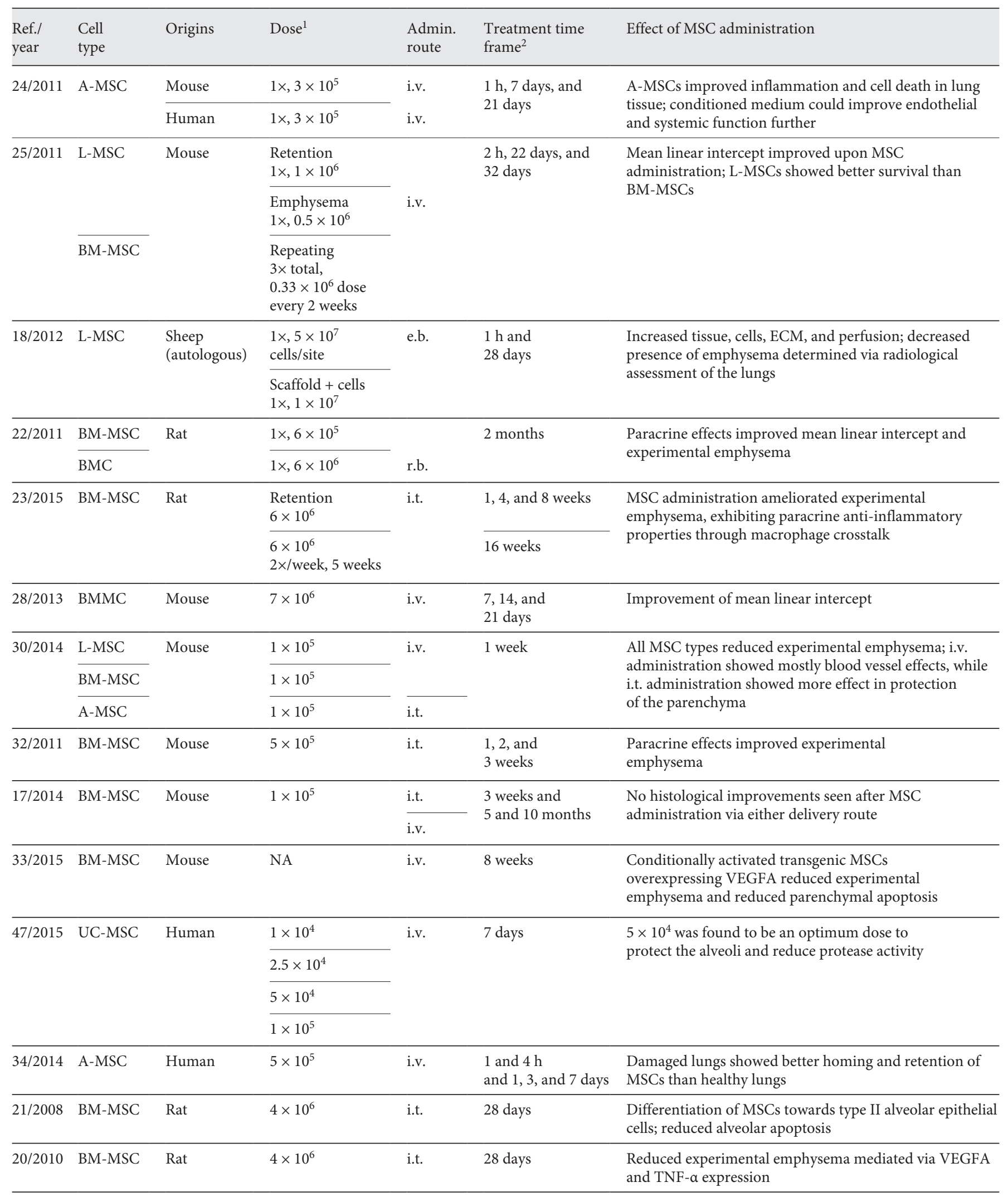


Table 2 (continued)

\begin{tabular}{|c|c|c|c|c|c|c|}
\hline $\begin{array}{l}\text { Ref./ } \\
\text { year }\end{array}$ & $\begin{array}{l}\text { Cell } \\
\text { type }\end{array}$ & Origins & Dose $^{1}$ & $\begin{array}{l}\text { Admin. } \\
\text { route }\end{array}$ & $\begin{array}{l}\text { Treatment time } \\
\text { frame }^{2}\end{array}$ & Effect of MSC administration \\
\hline $36 / 2006$ & A-MSC & Rat & $5 \times 10^{7}$ & i.v. & $\begin{array}{l}1,2,3 \text {, and } \\
4 \text { weeks }\end{array}$ & $\begin{array}{l}\text { MSCs improved experimental emphysema and boosted } \\
\text { vascularization of the lungs }\end{array}$ \\
\hline $35 / 2006$ & A-MSC & Rat & $5 \times 10^{7}$ & $\begin{array}{l}\text { Topical } \\
\text { (scaf- } \\
\text { fold) }\end{array}$ & $\begin{array}{l}1,2,3 \text {, and } \\
4 \text { weeks }\end{array}$ & $\begin{array}{l}\text { MSCs improved experimental emphysema in part by } \\
\text { endogenous MSC recruitment via HGF; improved blood } \\
\text { gas values and exercise tolerance }\end{array}$ \\
\hline
\end{tabular}

NA, not applicable; MSC, mesenchymal stromal cell; A-MSC, adipose-derived MSC; UC-MSC, umbilical cord-derived MSC; BMMSC, bone marrow-derived MSC; L-MSC, lung-derived MSC; BMC, bone marrow cell; BMMC, bone marrow mononuclear cell; Admin., administration; i.v., intravenous; e.b., endobronchial; r.b., retrobulbar; i.t., intratracheal; ECM, extracellular matrix; VEGFA, vascular endothelial growth factor; HGF, hepatocyte growth factor; TNF, tumor necrosis factor. ${ }^{1} 1 \times$ unless specified. ${ }^{2}$ After MSC administration.

Comparison of MSCs from Different Sources and

Using Different Routes of Administration

Regarding the source of MSCs, BM-MSCs of both animal and human origin have been the most commonly used MSCs in preclinical studies (Table 2). LonghiniDos-Santos et al. [28] showed that the population of cells isolated from bone marrow also contains fractions of hematopoietic stem cells as well as various mature lymphoid cells. This observation raises the question as to whether these subpopulations were also present in the bone marrow-derived populations used in the other studies listed in Table 2. It is unknown whether these populations are completely lost through selective culturing during the preparation of BM-MSCs and whether any remaining subpopulations may have had a significant effect on the results of the other studies. This lack of clarity regarding the homogeneity of the cell populations also shows that the setting of international criteria for the characterization of MSCs needs to be optimized.

Two other common sources being investigated for the treatment of emphysema are L-MSCs and adipose-derived MSCs (A-MSCs). In a mouse-based elastase model, mouse-derived L-MSCs were shown to display higher retention in the lungs than mouse-derived BM-MSCs [25]. In this study, both stem cell types showed similar expression profiles in terms of growth factor receptors and inflammatory mediators, and ameliorated elastase-induced lung damage. Nevertheless, L-MSCs showed a higher retention rate in the lungs than BM-MSCs, which may be explained by the higher expression of adhesion molecules such as ICAM-1, integrin- $\alpha_{2}$, and PDGFR $\alpha$, possibly enabling them to adhere to endothelial cells and to facilitate migration [25]. Thus, L-MSCs may be better equipped for local repair in lung disease than BM-MSCs. A-MSCs car- ry their own distinct advantage, being easily acquired in large volume when liposuction is available. In addition, they can be obtained in smaller numbers from subcutaneous adipose tissue deposits. This is especially relevant for future application in human patients, for whom collection of adipose tissue is often much less onerous than sampling of bone marrow or lung tissue. A-MSCs have been shown to interact with endothelial progenitor cells to rapidly form new blood vessels, a relevant feature for all forms of tissue regeneration and repair [29].

In a study comparing the effects of intravenous and intratracheal installation of A-MSCs, L-MSCs, and BMMSCs in a mouse model, regardless of the administration route, all types reduced the mean linear intercept, neutrophil infiltration, and alveolar epithelial and endothelial cell damage induced by elastase and increased elastic fiber content. Only BM-MSCs displayed beneficial systemic effects, while A-MSCs and L-MSCs showed a more significant reduction in the fractional area of alveolar collapse than BM-MSCs [30]. Another study compared human LMSCs and BM-MSCs in vitro and observed that L-MSCs expressed higher levels of the stemness-related marker nestin, which may have consequences for their ability to differentiate into different cell types [31].

With respect to the delivery route, in contrast to intravenous administration, intratracheal MSC administration further reduced alveolar hyperinflation and the collagen fiber content in this model [30]. Engraftment, survival, and persistence of administered MSCs were investigated in 11 of the 16 animal studies included in this review [18, 21, 23-25, 28, 32-36], using methods such as fluorescence tracking or using cross-gender administration of MSCs. There has been much dispute over retention times, with Eggenhofer et al. [37] claiming there is no 
viable MSC retention after $24 \mathrm{~h}$ in lungs administered via the tail vein. These findings are in contrast with the results from Hoffman et al. [25], who showed retention of at least 4 days also after administration via the tail vein. Six of the other studies agree with Hoffman et al. [25] that retention of MSCs beyond $24 \mathrm{~h}$ is possible, while the 5 others did not state this specifically or did not examine retention beyond $24 \mathrm{~h}$. Eggenhofer et al. [37] argued that the extended retention times observed in other studies are actually due to nonviable fragments of labeled MSCs or from phagocytosed cells, leading to a false-positive result. Another interesting observation was made using quantum dot-labelled MSCs, showing that intravenously injected MSCs were well tolerated and showed better 7-day retention in lungs with emphysema as opposed to healthy lungs [34]. This indicates that lung tissue damage may be required to support tissue persistence. In their ovine study, Ingenito et al. [18] showed that upon endobronchial administration of autologous L-MSCs, only a small fraction of stem cells were retained in the lungs, and after 4 weeks only few surviving MSCs could be detected. This led the authors to recommend further research into the development of scaffold structures that can represent an optimized local environment for MSC adherence, retention, and survival.

In the study of Antunes et al. [30], injection of L-MSCs via the right jugular vein led to the death of all injected mice, which was not observed after intravenous administration of either A-MSCs or BM-MSCs in this study. In contrast, intravenous injection of L-MSCs into the tail vein, as demonstrated by Hoffman et al. [25], did not lead to lethality. Therefore, lethality of MSC administration might not be a species-specific limitation, but rather a consequence of the location of injection [25].

Together, these animal studies show that both intravenous and intratracheal delivery of MSCs can reduce histological hallmarks of emphysema, although intravenous delivery may exhibit a greater systemic effect, dampening inflammation. Furthermore, retention of the different MSC types is still limited and requires optimization, although it may be optimal for L-MSCs. However, intravenous injection of L-MSCs specifically may be more risky and lead to lethality.

\section{MSC Administration in Human Emphysema}

It is surprising that with the limited fundamental knowledge gained from the animal experiments, studies have already been conducted testing MSCs in patients with emphysema. The first safety trial was conducted in 2009 and included 4 patients with severe emphysema undergoing intravenous administration of $5 \times 10^{9}$ mononuclear bone marrow cells [38]. The treatment was well tolerated, and after 12 months an increase in quality of life was noted. However, physical health parameters such as lung function or 6-min walk test results did not show any improvement. Then, in 2013, the first prospective, double-blind, placebo-controlled trial was published [39]. This study included 62 severe emphysema patients who received, in 30-day intervals, 4 times an infusion of either placebo or $100 \times 10^{6} \mathrm{BM}-\mathrm{MSC}$ isolated from healthy donors, and they were followed up for 2 years. Again, the administration was safe and no side effects were reported among the 32 actively treated patients, but no improvements in lung function, quality of life, or exacerbation incidence were observed. A post hoc analysis revealed that those patients admitted with a CRP titer $>4 \mathrm{mg} / \mathrm{L}$ showed a significant reduction in CRP level in the first month of treatment, with a continuing trend in the remainder of the follow-up period. The authors proposed that this study forms an important basis for future research; however, overall the clinical results were not very promising, with only a mild systemic anti-inflammatory effect. In a more recent phase I clinical trial, 8 severe emphysema patients received $60-140 \times 10^{6}$ autologous BM-MSCs [40]. This treatment was similarly well tolerated and a 3-fold increase in the platelet and endothelial marker CD31 was found within the alveolar septa 3 weeks after infusion. This would suggest better perfusion of the lungs, possibly leading to improved lung function.

It may be anticipated that the use of autologous cells is disadvantageous in the treatment of COPD, because especially lung-derived cells from COPD patients may be subjected to oxidative stress and/or accelerated ageing, leading to exhaustion of their stemness $[2,9]$. BM-MSCs from aged humans have been shown to express markers of cellular senescence and exhaustion [41]. Broekman et al. [42] did not find any functional differences between COPD and control-derived BM-MSCs (e.g., with respect to growth factor expression). However, more extensive studies on differences between L-MSCs from COPD patients and those from controls in comparison with MSCs from other sources are awaited.

Moreover, especially in a disease such as severe emphysema, the relatively enlarged air spaces with marginal blood supply can complicate the efficacy of stem cell treatment. Therefore, the use of a hydrogel scaffold could be taken into consideration. Together, further studies on 
Fig. 2. Example of artificial alveolar scaffolds. Faraj et al. [46] developed a procedure to create mimics of alveolar structures, using a slow-freezing technique on a suspension of insoluble collagen fibers. a, b Different magnifications of natural scaffolds of alveolar tissue. The letters "a" illustrate the alveolar sack-like structures. c, d Different magnifications of artificial scaffolds. Scale bars, $100 \mu \mathrm{m}$. Illustration reproduced with permission [46].

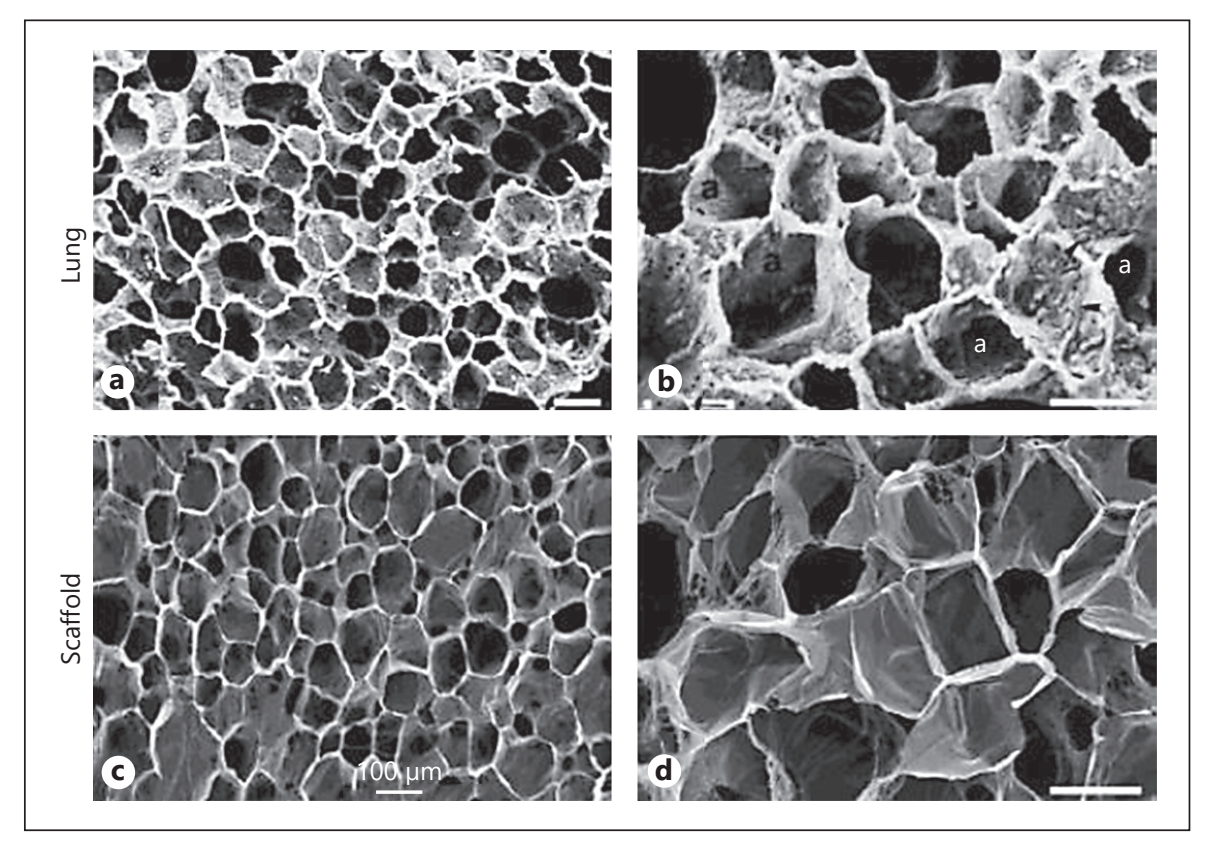

the source (e.g., BM-MSCs vs. L-MSCs, as described above), dosage, MSC preconditioning, administration route, and use of scaffolds are warranted.

\section{Another Concept: Ex vivo Construction of "New Lungs"}

The local microenvironment of the lungs, consisting among others of ECM fibers and proteoglycans, is severely impaired in emphysema. Increased damage to or impaired repair of the ECM as a consequence of intrinsic defects in key supporting cell types in COPD may lead to abnormalities in and/or loss of specific ECM proteins. Stem cells, administered either intravenously or locally, may need additional clues to be able to engraft in emphysematous lungs, as integrin binding to ECM molecules is essential for their adhesion, survival, and function. Thus ECM abnormalities may lead to a reduced capacity of both autologous and allogenic stem cells to be retained and to regenerate lung tissue. Perhaps the key to the successful implantation of stem cells in lungs therefore lies in an improvement of the ECM microenvironment - for instance, by the use of a bioactive scaffold [43]. Currently, two promising, but challenging, approaches are being explored concerning an optimization of the local environment for stem cell treatment.

First, a "natural" scaffold can be acquired by removing all cells from a donor lung in a process called decellular- ization. Subsequently, a hydrogel can be generated from decellularized normal lung ECM which can be used as a carrier component and to provide a healthy microenvironment for injected MSCs [44]. The main advantage of using lung material from a healthy donor is that this type of lung hydrogel scaffold does not incite a foreign body response or contain any of the remodeled fibers observed in COPD. This approach theoretically allows for compensation of any damaged or lost ECM components to improve retention and repair in COPD lungs through MSC integrin binding.

Some researchers are also focusing on recellularization of whole lung ECM in order to generate transplantable lung tissue ex vivo; however, although theoretically possible, it is unlikely to be successful at this early stage. As an example of this application, using a rat model Song et al. [45] made use of decellularized lungs in a bioreactor to facilitate the recellularization of lung scaffolds ex vivo.

Finally, soluble isolated ECM component fibers can be used to generate an artificial bioscaffold to mimic the native environment including its 3D structure (Fig. 2). While these structures also allow for binding of additional growth factors, the size and rigidity of the structures may be a future challenge when moving to a more patient-orientated setting. A hydrogel consisting of small ECM particles will most likely be an intermediate approach explored in the future. 


\section{Conclusions}

It is currently too early to convey optimistic messages about effective stem cell therapies for severe emphysema patients. At present, the authors encourage the emphysema patient community to avoid MSC therapy offers, as their effectiveness cannot be guaranteed yet. Interested patients could instead participate in scientifically oriented clinical trials of MSCs, such as the ones offered on www.clinicaltrials.gov. Before the administration of autologous MSCs can be considered in a phase I study, essential preclinical questions have to be resolved, including whether there is an emphysema-specific deficit of MSCs and how we could tackle this ex vivo. In addition, we need to gain insight into the optimal source of MSCs, the best route to administer MSCs, and which doses and frequencies are needed to be successful. Furthermore, we should investigate how the engraftment, survival, and functioning of donated MSCs can be improved - for instance, by the use of a bioactive scaffold. If we can answer these questions, treatment with MSCs will take another important step.

\section{Financial Disclosure and Conflicts of Interest}

The authors have no conflicts of interest to disclose.

\section{References}

1 Rolandsson S, Karlsson JC, Scheding S, Westergren-Thorsson G: Specific subsets of mesenchymal stroma cells to treat lung disorders - finding the Holy Grail. Pulm Pharmacol Ther 2014;29:93-95.

-2 Shi W, Chen F, Cardoso WV: Mechanisms of lung development: contribution to adult lung disease and relevance to chronic obstructive pulmonary disease. Proc Am Thorac Soc 2009;6:558-563.

3 Hogg JC, Timens W: The pathology of chronic obstructive pulmonary disease. Annu Rev Pathol 2009;4:435-459.

4 Postma DS, Timens W: Remodeling in asthma and chronic obstructive pulmonary disease. Proc Am Thorac Soc 2006;3:434-439.

5 Monto AS, Higgins MW, Ross HW: The Tecumseh Study of Respiratory Illness. VIII. Acute infection in chronic respiratory disease and comparison groups. Am Rev Respir Dis 1975;111:27-36.

-6 Anthonisen NR, Manfreda J, Warren CP, Hershfield ES, Harding GK, Nelson NA: Antibiotic therapy in exacerbations of chronic obstructive pulmonary disease. Ann Intern Med 1987;106:196-204.

7 van Straaten JF, Coers W, Noordhoek JA, Huitema S, Flipsen JT, Kauffman HF, et al: Proteoglycan changes in the extracellular matrix of lung tissue from patients with pulmonary emphysema. Mod Pathol 1999;12:697705.

8 Plataki M, Tzortzaki E, Rytila P, Demosthenes M, Koutsopoulos A, Siafakas NM: Apoptotic mechanisms in the pathogenesis of COPD. Int J Chron Obstruct Pulmon Dis 2006;1:161-171.

9 Mercado N, Ito K, Barnes PJ: Accelerated ageing of the lung in COPD: new concepts. Tho$\operatorname{rax} 2015 ; 70: 482-489$.

10 Kajstura J, Rota M, Hall SR, Hosoda T, D’Amario D, Sanada F, et al: Evidence for hu- man lung stem cells. N Engl J Med 2011;364: 1795-1806.

-11 Kotton DN: Next-generation regeneration: the hope and hype of lung stem cell research. Am J Respir Crit Care Med 2012;185:12551260.

12 Dominici M, Le Blanc K, Mueller I, SlaperCortenbach I, Marini F, Krause D, et al: Minimal criteria for defining multipotent mesenchymal stromal cells. The International Society for Cellular Therapy position statement. Cytotherapy 2006;8:315-317.

$\checkmark 13$ Liu A, Chen S, Cai S, Dong L, Liu L, Yang Y, et al: Wnt5a through noncanonical Wnt/JNK or Wnt/PKC signaling contributes to the differentiation of mesenchymal stem cells into type II alveolar epithelial cells in vitro. PLoS One 2014;9:e90229.

14 Gong X, Sun Z, Cui D, Xu X, Zhu H, Wang L, et al: Isolation and characterization of lung resident mesenchymal stem cells capable of differentiating into alveolar epithelial type II cells. Cell Biol Int 2014;38:405-411.

15 Antunes MA, Rocco PRM: Elastase-induced pulmonary emphysema: insights from experimental models. An Acad Bras Cienc 2011;83: 1385-1396.

16 Annoni R, Lanças T, Yukimatsu Tanigawa R, de Medeiros Matsushita M, de Morais Fernezlian S, Fernezlian M, et al: Extracellular matrix composition in COPD. Eur Respir J 2012;40:1362-1373.

17 Tibboel J, Keijzer R, Reiss I, de Jongste JC, Post M: Intravenous and intratracheal mesenchymal stromal cell injection in a mouse model of pulmonary emphysema. COPD 2014;11:310-318.

18 Ingenito EP, Tsai L, Murthy S, Tyagi S, Mazan M, Hoffman A: Autologous lung-derived mesenchymal stem cell transplantation in experimental emphysema. Cell Transplant 2012;21:175-189.
19 Kennelly H, Mahon BP, English K: Human mesenchymal stromal cells exert HGF dependent cytoprotective effects in a human relevant pre-clinical model of COPD. Sci Rep 2016;6:38207.

20 Zhen G, Xue Z, Zhao J, Gu N, Tang Z, Xu Y, et al: Mesenchymal stem cell transplantation increases expression of vascular endothelial growth factor in papain-induced emphysematous lungs and inhibits apoptosis of lung cells. Cytotherapy 2010;12:605-614.

21 Zhen G, Liu H, Gu N, Zhang H, Xu Y, Zhang Z: Mesenchymal stem cells transplantation protects against rat pulmonary emphysema. Front Biosci 2008;13:3415-3422.

22 Huh JW, Kim S-Y, Lee JH, Lee J-S, Van Ta Q, Kim M, et al: Bone marrow cells repair cigarette smoke-induced emphysema in rats. Am J Physiol Lung Cell Mol Physiol 2011; 301:L255-L266.

23 Gu W, Song L, Li X-M, Wang D, Guo X-J, Xu W-G: Mesenchymal stem cells alleviate airway inflammation and emphysema in COPD through down-regulation of cyclooxygenase- 2 via p38 and ERK MAPK pathways. Sci Rep 2015;5:8733.

24 Schweitzer KS, Johnstone BH, Garrison J, Rush NI, Cooper S, Traktuev DO, et al: Adipose stem cell treatment in mice attenuates lung and systemic injury induced by cigarette smoking. Am J Respir Crit Care Med 2011; 183:215-225.

25 Hoffman AM, Paxson JA, Mazan MR, Davis AM, Tyagi S, Murthy S, et al: Lung-derived mesenchymal stromal cell post-transplantation survival, persistence, paracrine expression, and repair of elastase-injured lung. Stem Cells Dev 2011;20:1779-1792.

26 Mizumura K, Cloonan SM, Nakahira K, Bhashyam AR, Cervo M, Kitada T, et al: Mitophagy-dependent necroptosis contributes to the pathogenesis of COPD. J Clin Invest 2014;124:3987-4003. 
27 Li X, Zhang Y, Yeung SC, Liang Y, Liang X, Ding Y, et al: Mitochondrial transfer of induced pluripotent stem cell-derived mesenchymal stem cells to airway epithelial cells attenuates cigarette smoke-induced damage. Am J Respir Cell Mol Biol 2014;51:455-465.

-28 Longhini-Dos-Santos N, Barbosa-de-Oliveira VA, Kozma RH, Faria CA, Stessuk T, Frei F, et al: Cell therapy with bone marrow mononuclear cells in elastase-induced pulmonary emphysema. Stem Cell Rev 2013;9:210-218.

29 Traktuev DO, Prater DN, Merfeld-Clauss S, Sanjeevaiah AR, Saadatzadeh MR, Murphy $\mathrm{M}$, et al: Robust functional vascular network formation in vivo by cooperation of adipose progenitor and endothelial cells. Circ Res 2009;104:1410-1420.

-30 Antunes MA, Abreu SC, Cruz FF, Teixeira AC, Lopes-Pacheco M, Bandeira E, et al: Effects of different mesenchymal stromal cell sources and delivery routes in experimental emphysema. Respir Res 2014;15:118.

- 31 Ricciardi M, Malpeli G, Bifari F, Bassi G, Pacelli L, Nwabo Kamdje AH, et al: Comparison of epithelial differentiation and immune regulatory properties of mesenchymal stromal cells derived from human lung and bone marrow. PLoS One 2012;7:e35639.

- 32 Katsha AM, Ohkouchi S, Xin H, Kanehira M, Sun R, Nukiwa T, et al: Paracrine factors of multipotent stromal cells ameliorate lung injury in an elastase-induced emphysema model. Mol Ther 2011;19:196-203.

-33 Chen YB, Lan YW, Chen LG, Huang TT, Choo KB, Cheng WT, et al: Mesenchymal stem cell-based HSP70 promoter-driven VEGFA induction by resveratrol alleviates elastase-induced emphysema in a mouse model. Cell Stress Chaperones 2015;20:979989.
Kim YS, Kim JY, Shin DM, Huh JW, Lee SW, Oh YM: Tracking intravenous adipose-derived mesenchymal stem cells in a model of elastase-induced emphysema. Tuberc Respir Dis (Seoul) 2014;77:116-123.

35 Shigemura N, Okumura M, Mizuno S, Imanishi Y, Matsuyama A, Shiono H, et al: Lung tissue engineering technique with adipose stromal cells improves surgical outcome for pulmonary emphysema. Am J Respir Crit Care Med 2006;174:1199-1205.

36 Shigemura N, Okumura M, Mizuno S, Imanishi Y, Nakamura T, Sawa Y: Autologous transplantation of adipose tissue-derived stromal cells ameliorates pulmonary emphysema. Am J Transplant 2006;6:2592-2600.

-37 Eggenhofer E, Benseler V, Kroemer A, Popp FC, Geissler EK, Schlitt HJ, et al: Mesenchymal stem cells are short-lived and do not migrate beyond the lungs after intravenous infusion. Front Immunol 2012;3:297.

38 Ribeiro-Paes JT, Bilaqui A, Greco OT, Ruiz MA, Marcelino MY, Stessuk T, et al: Unicentric study of cell therapy in chronic obstructive pulmonary disease/pulmonary emphysema. Int J Chron Obstruct Pulmon Dis 2011; 6:63-71.

-39 Weiss DJ, Casaburi R, Flannery R, LeRouxWilliams M, Tashkin DP: A placebo-controlled, randomized trial of mesenchymal stem cells in COPD. Chest 2013;143:15901598 .
40 Stolk J, Broekman W, Mauad T, Zwaginga JJ, Roelofs H, Fibbe WE, et al: A phase I study for intravenous autologous mesenchymal stromal cell administration to patients with severe emphysema. QJM 2016;109:331-336.

41 Cheng H, Qiu L, Ma J, Zhang H, Cheng M, Li $\mathrm{W}$, et al: Replicative senescence of human bone marrow and umbilical cord derived mesenchymal stem cells and their differentiation to adipocytes and osteoblasts. Mol Biol Rep 2011;38:5161-5168.

42 Broekman W, Roelofs H, Zarcone MC, Taube C, Stolk J, Hiemstra PS: Functional characterisation of bone marrow-derived mesenchymal stromal cells from COPD patients. ERJ Open Res 2016;2:00045-2015.

43 Brouwer KM, Hoogenkamp HR, Daamen WF, van Kuppevelt TH: Regenerative medicine for the respiratory system: distant future or tomorrow's treatment? Am J Respir Crit Care Med 2013;187:468-475.

44 Pouliot RA, Link PA, Mikhaiel NS, Schneck MB, Valentine MS, Kamga Gninzeko FJ, et al: Development and characterization of a naturally derived lung extracellular matrix hydrogel. J Biomed Mater Res A 2016;104:19221935.

45 Song JJ, Kim SS, Liu Z, Madsen JC, Mathisen DJ, Vacanti JP, et al: Enhanced in vivo function of bioartificial lungs in rats. Ann Thorac Surg 2011;92:998-1006.

-46 Faraj KA, van Kuppevelt TH, Daamen WF: Construction of collagen scaffolds that mimic the three-dimensional architecture of specific tissues. Tissue Eng 2007;13:2387-2394.

-47 Kim Y-S, Kim J-Y, Huh JW, Lee SW, Choi SJ, Oh Y-M: The therapeutic effects of optimal dose of mesenchymal stem cells in a murine model of an elastase induced-emphysema. Tuberc Respir Dis (Seoul) 2015;78:239-245. 